\title{
WAVE ENERGY CONVERTER WITH WAVE ABSORBING CONTROL
}

\author{
Takashi Kawaguchi ${ }^{1}$, Kunio Nakano ${ }^{2}$, Shogo Miyajima ${ }^{3}$, and Taro Arikawa ${ }^{4}$
}

\begin{abstract}
The wave absorbing control using wave sensors was theorized and developed by one of the authors, about 30 years ago. It was originally for absorbing wavemakers for tank tests in laboratories. This control enables wavemakers to generate the desired incident waves while absorbing undesirable reflected waves from the tank wall. When waves are absorbed by the wavemaker, the energy of the waves are also absorbed, that is, the energy is regenerated to electric power with the wavemaker drive-motor. According to this theory, in case that certain waves are generated by an oscillating body, these waves can be absorbed by the same body. Therefore, we can design a wave energy converter (WEC) as a kind of absorbing wavemaker.
\end{abstract}

Keywords: wave power; wave energy; wave absorption and generation; resonance control; point absorber; absorbing wavemaker

\section{INTRODUCTION}

Absorption wavemaker was developed by Salter for tank model testing of Salter Duck. (Salter, 1974; Salter, 1984) One of the authors theorized absorption wavemakers based on velocity potential theory more than 30 years ago. (Kawaguchi, 1986; Hirakuchi et al., 1990) After then, most of wavemakers in Japan becomes absorption type, as shown in Figure 1. (Tanizawa et al., 2011)

They say that the wavemakers can absorb more than $97 \%$ in energy of incoming regular waves of 0.85 to $2.53 \mathrm{~s}$ in period., and $85 \%$ for other waves. Also, it is also said that they can absorb $85 \%$ of the energy of the 45-degree oblique incident wave with a wavelength of $5 \mathrm{~m}$. Such technology may be useful for wave energy converters.

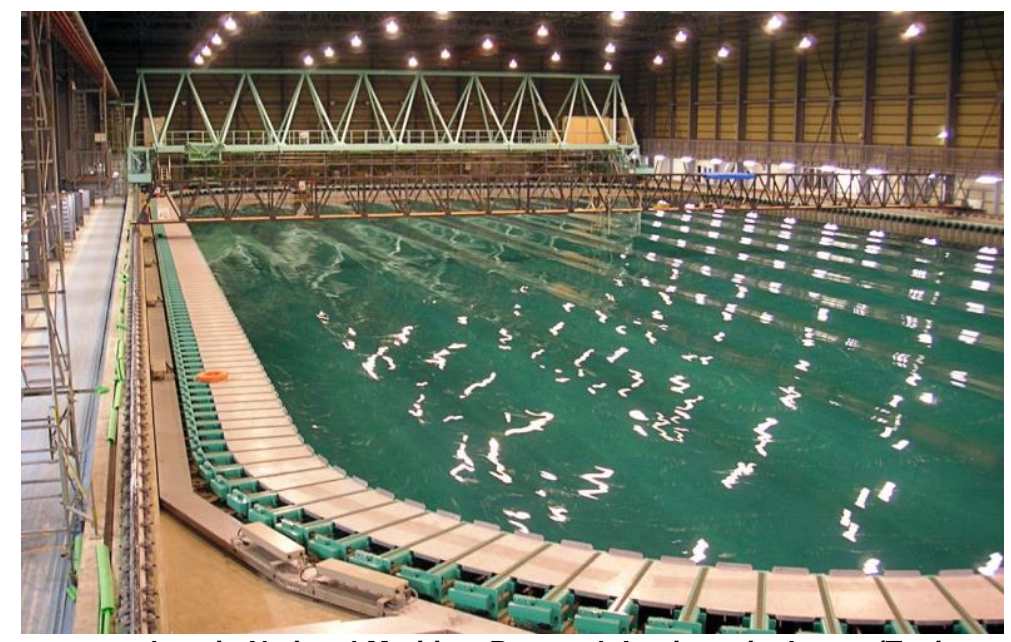

Figure 1. Absorption wavemakers in National Maritime Research Institute, in Japan. (Tanizawa et al., 2011)

\section{ABSORPTION VS. RESONANCE}

Falnes explained the principle for capture of wave energy according to the following figures. As shown in Figure 2, if we can generate waves to cancel the reflected waves by moving wall properly, all incident waves are absorbed by the tank wall. In this process, the energy of incident waves is absorbed through the movement of the wall.

Therefore, they say that absorption of wave energy from the sea may be considered as a phenomenon of wave interference. Then wave energy absorption may be described by an apparently paradoxical statement:

To absorb a wave means to generate a wave or, in other words:

To destroy a wave is to create a wave.

\footnotetext{
${ }^{1}$ Aqusys Corporation, 2-26-9-301, Higashi-komatsugawa, Edogawaku, Tokyo, 1320033, Japan

${ }_{2}^{2}$ Mitsui E\&S Steel Structures Engineering Co., Ltd., 3, Hiyoshibaru, Oita, 8700395, Japan

${ }_{3}$ Akishima Laboratories (Mitsui Zosen) Inc., 1-1-50, Tsutsujigaoka, Akishima, Tokyo, 1960012, Japan

${ }^{4}$ Department of Civil and Environmental Engineering, Chuo University, 1-13-27 Kasuga, Tokyo, 1128551, Japan
} 


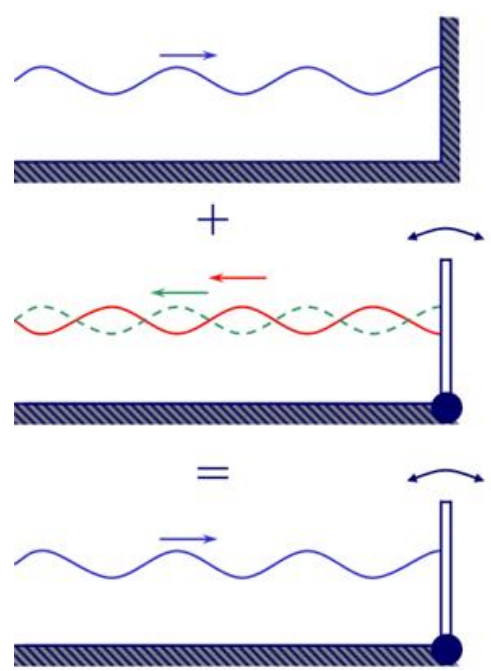

Incident wave

Wave reflected from fixed wall

Wave generation on otherwise

calm water (due to wall oscillation)

Result: The incident wave is absorbed by the moving wall because the reflected wave is cancelled by the generated wave.

Figure 2. "To absorb a wave means to generate a wave" or "to destroy a wave means to create a wave".

(Falnes 2002, Hals 2002)

They also found that the such absorption is caused at resonance. (Budal and Falnes, 1975) Figure 3 shows two types of control: one is reactive control and the other is phase control by latch. The reactive control is an optimal control and the latching control is a sub-optimal control. Falnes (2002) shows the difference of performance between 3 types of control, by comparing accumulated energy, as shown in Figure.4.

Though the reactive control is the best solution, how to realize the reactive control is not yet founded.

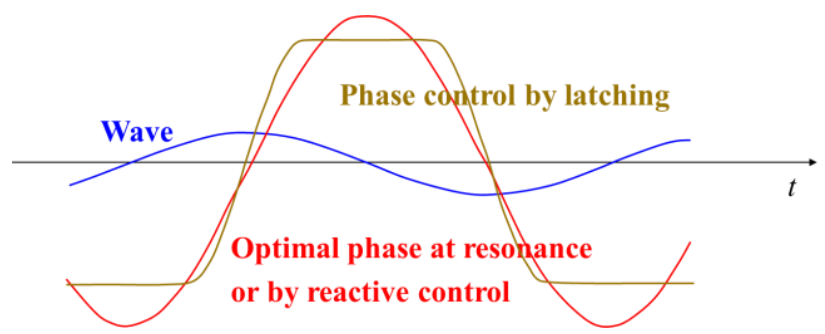

Figure 3. Wave and heave motion of float. (Falnes 2002)

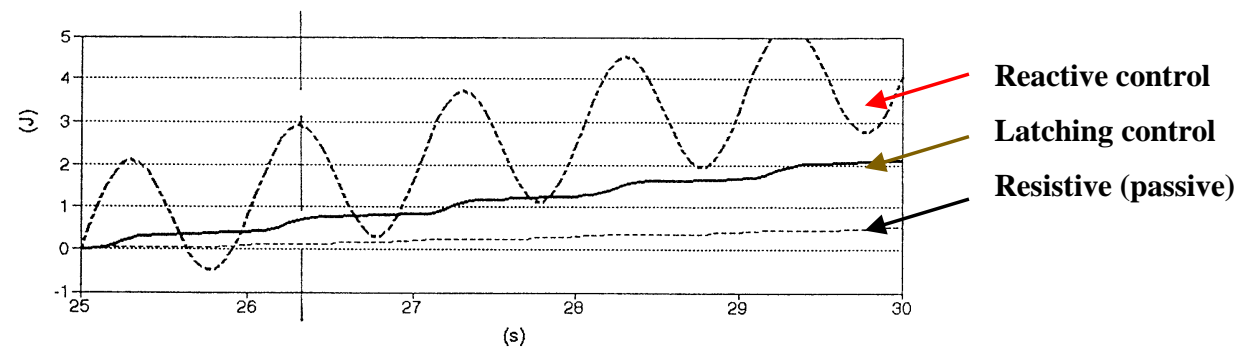

Figure 4. Accumulation of energy by oscillating body. (Falnes 2002)

\section{OPTIMAL VELOCITY CONTROL}

Absorption wavemaker was developed by Salter for tank model testing of Salter Duck. (Salter, 1974; Salter, 1984) One of the authors theorized absorption wavemakers based on velocity potential theory more than 30 years ago. (Kawaguchi, 1986; Hirakuchi et al., 1990) 


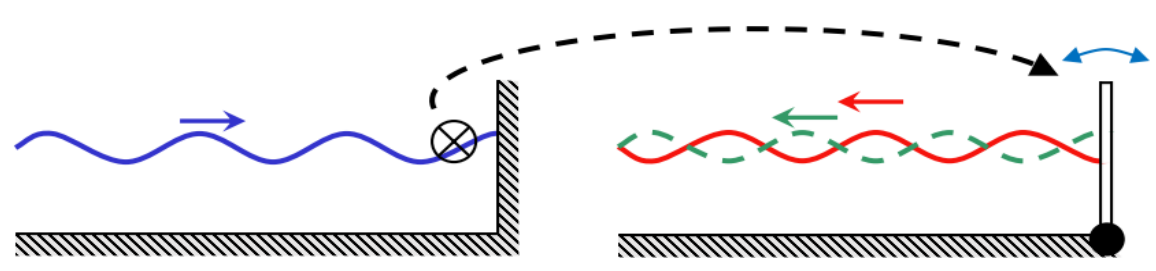

Figure 5. Wave absorption with wave sensor feedback. (Kawaguchi, 1986)

This theory is originally made for wavemakers with pitching or surging plate, as shown in Figure 6 . (Kawaguchi, 1986; Hirakuchi et al., 1990) If there is no water behind the waveboards, there is no difference between absorbing wavemakers and WECs. However, if there is water behind the plate, as shown in Figure 6, waves must be generated behind the plate by absorbing motion of the plate. In such case, the captured energy in front of the plate is to be consumed behind the plate. It means the total captured energy becomes zero. From the viewpoint of maximum capture of wave energy, the best solution is to absorb 50\% energy of the incident waves, reflecting waves of $25 \%$ energy and transmitting waves of $25 \%$ energy backwards.

In such cases, WEC control formula is expressed as follows: (Kawaguchi et al., 2018)

$$
\dot{X}=-\frac{\omega}{2 \bar{A}} \eta_{I \cdot x=0}
$$

Here, $\bar{A}$ is referred as the amplitude characteristics of transfer function in control engineering, or it is called as the ratio of amplitude operator (RAO) in marine engineering.

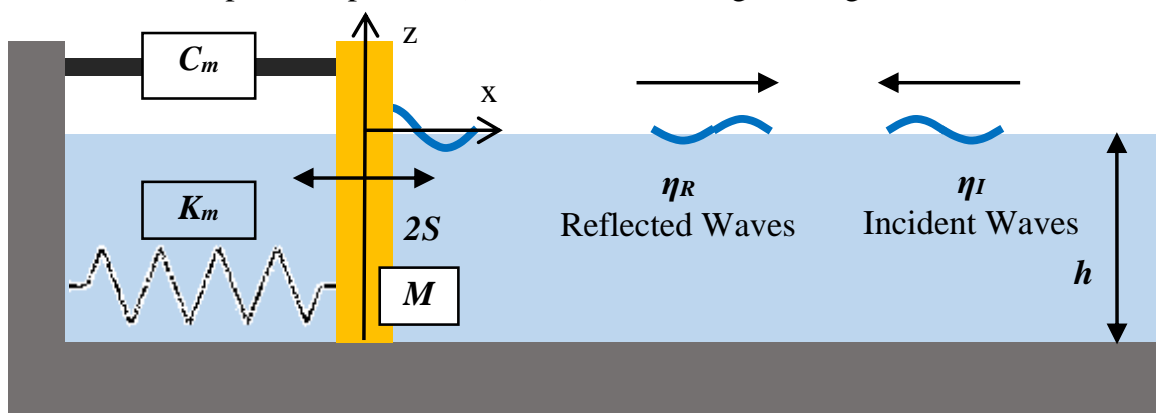

Figure 6. Schematic diagram of WEC with surging motion.

As for the heaving WECs as shown in the Figure 7, this formula is transformed as follows:

$$
\dot{Z}=\frac{\omega}{2 \bar{A}} \eta_{I . x=0}
$$

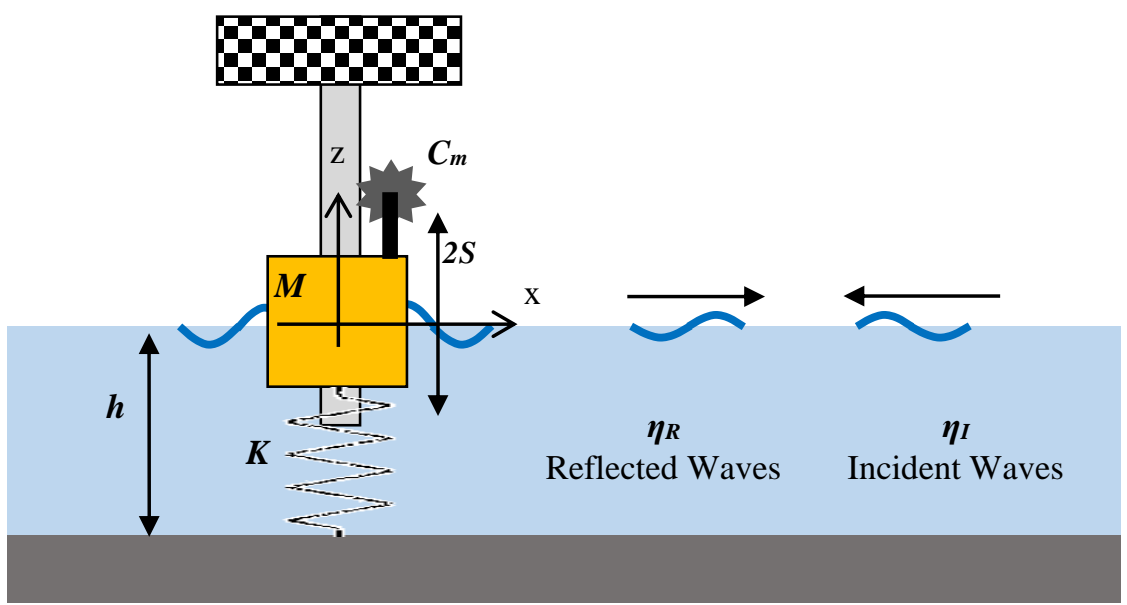

Figure 7. Schematic diagram of WEC with heaving motion 


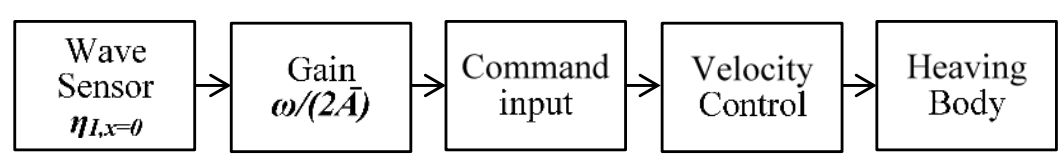

Figure 8. Block diagram of the optimal velocity control.

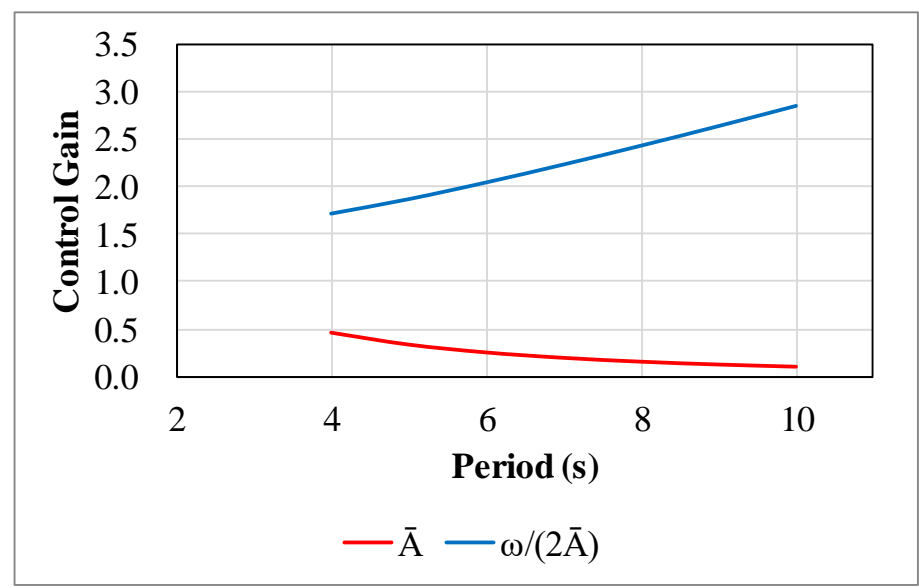

Figure 9. Calculated values of $\bar{A}$ and $\omega /(2 \bar{A})$.

We use the control diagram shown in Figure 8. When using digital control, the control interval should be short. We decided to control every $0.1 \mathrm{~s}$, considering that period of ocean waves is 5 to $15 \mathrm{~s}$. The control shown in Figure 8 is executed every $0.1 \mathrm{~s}$.

Control coefficients $\bar{A}$ and $\omega /(2 \bar{A})$ shown in the Figure 9 were calculated numerically in advance, based on the WEC dimensions. (Kobayashi et al., 1974) Since the values of $\omega /(2 \bar{A})$ are ranging 2.0 to 2.8 within wave period from 6 to $10 \mathrm{~s}$, initial value of $\omega /(2 \bar{A})$ is to be around 2.5 . However, these values are to be tuned in the trial operation.

\section{TANK MODEL TEST}

\section{Specifications of Test WEC}

Specifications of the tested WEC are as follows.

$\begin{array}{ll}\text { Type of WEC } & \text { Heaving with box float } \\ \text { Mean Water Depth } & 7 \mathrm{~m} \\ \text { Dimensions of Box Float } & 2.5 \mathrm{~m}(\mathrm{w}), 3.2 \mathrm{~m}(\mathrm{D}), 3 \mathrm{~m}(\mathrm{H}) \\ \text { Generator Rated Output } & 10 \mathrm{~kW} \text { x } 2 \mathrm{setts} \\ \text { Rated Torque } & 50 \mathrm{Nm} \text { x } 2 \\ \text { Rated RPM } & 2000 \mathrm{RPM} \\ \text { Max. Heaving Force } & \text { appr. } 20 \mathrm{kN} \times 2 \\ \text { Max. Heaving Velocity } & \text { appr. } 1 \mathrm{~m} / \mathrm{s}\end{array}$

\section{Power Generation Test}

We performed tank tests with a $1 / 5$ scale model WEC capable of the optimal velocity control with a small servomotor and a wave sensor. Regular waves of $0.2 \mathrm{~m}$ wave height were used, corresponding to $1 \mathrm{~m}$ wave height in real sea. In order to investigate the influence of the incident angle, a model test was conducted for both incident angles of 0-degree and 45-degrees. Since there is no difference in the results of the two tests, we decided that box float can be used as a substitute for axisymmetric float.

Figure 11 shows the resonance phenomena clearly. Compared with the wave profile, amplitude of the float position is double, and the phase is delayed 90 degree. Figure 12 shows wave energy generated from the tank waves, repeating regenerating and motoring. Figure 13 shows a typical energy curve showing reactive control explained by Falnes (2002). These data show that the optimal velocity control is highly effective. 


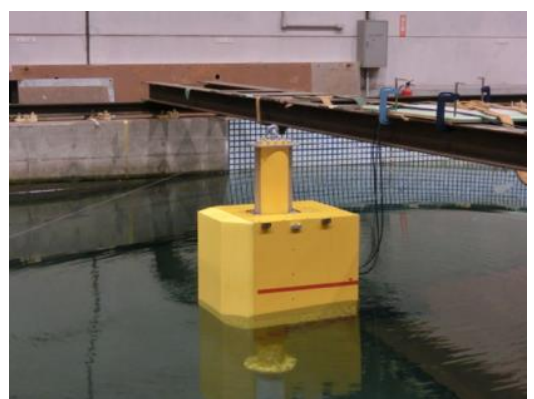

Figure 10. 1/5 scale model WEC capable of the optimal velocity control with a servomotor and a wave sensor.

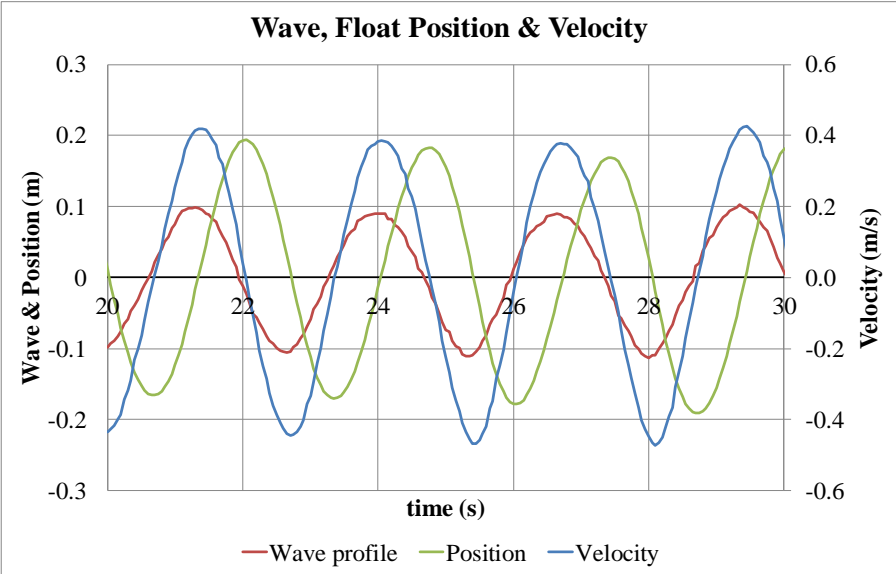

Figure 11. Resonance done with $1 / 5$ scale model WEC.

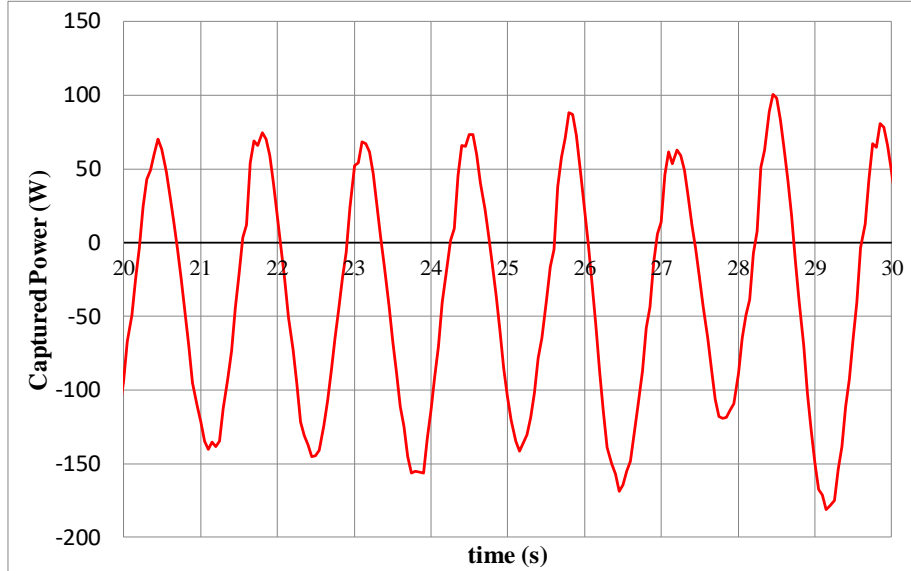

Figure 12. Power generation with $1 / 5$ scale model WEC.

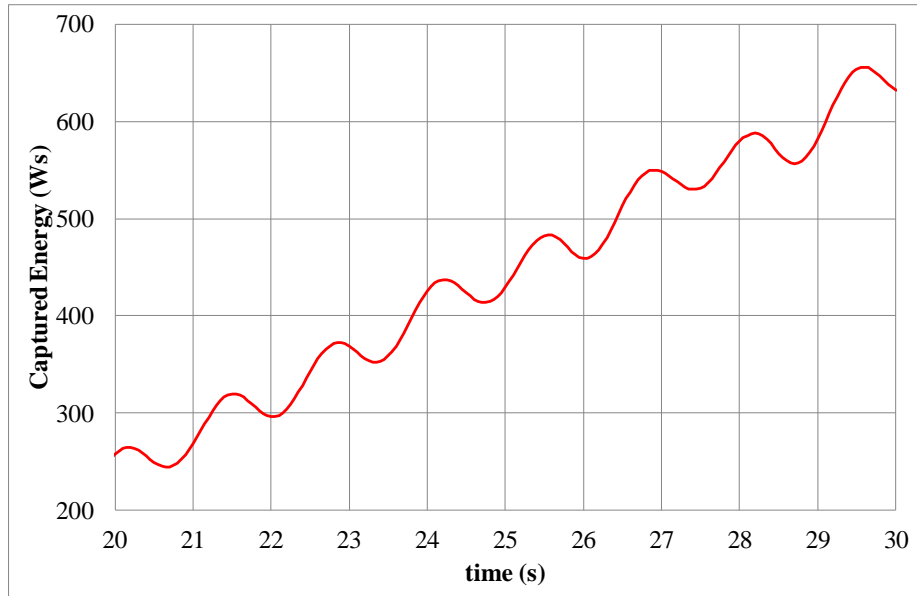

Figure 13. Integrated power with $\mathbf{1 / 5}$ scale model WEC (J=Ws). 


\section{Capture Width Ratio of Box Float}

The maximum energy which may be absorbed by a heaving axisymmetric body is equal to the energy delivered by the incident wave front of width equal to the wavelength divided by $2 \pi$. Thus, for a heaving axisymmetric body, the maximum capture width, Cmax, may be expressed as shown in Eq. (3).

Capture width is the ratio of the absorbed power to the incident wave power resource. Capture width ratio $\boldsymbol{C W R}$ is the ratio of the capture width to the typical length of the device. (Eq. 5) (Babarit and Hals, 2011)

$$
\begin{gathered}
C \max =\frac{P_{a b s \cdot \max }}{P w}=\frac{1}{k_{0}} \equiv \frac{\lambda}{2 \pi} \\
C=\frac{P_{a b s}}{P w} \\
C W R=\frac{P_{a b s}}{P w \cdot B}
\end{gathered}
$$

The test for capture width ratio is performed for 2 different incident angles, 0-degree angle and 45degree angle. The results of 2 cases are Figure 14 and 15.

The efficiency of the WEC seems to be high, since values of capture width ratio are ranging between 0.6 and 1.3. Moreover, since the difference between 2 cases is very small, it is reasonable to use a box float instead of an axisymmetric float.

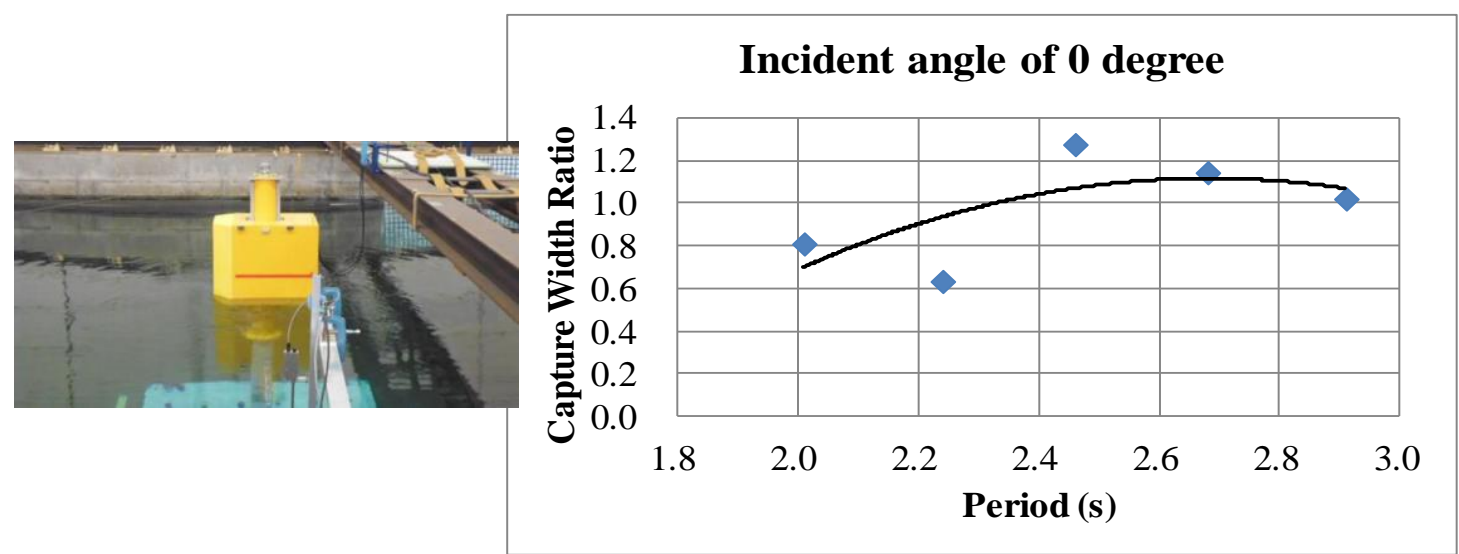

Figure 14. Capture width ratio of the WEC model, for incident wave angle of 0-degree.

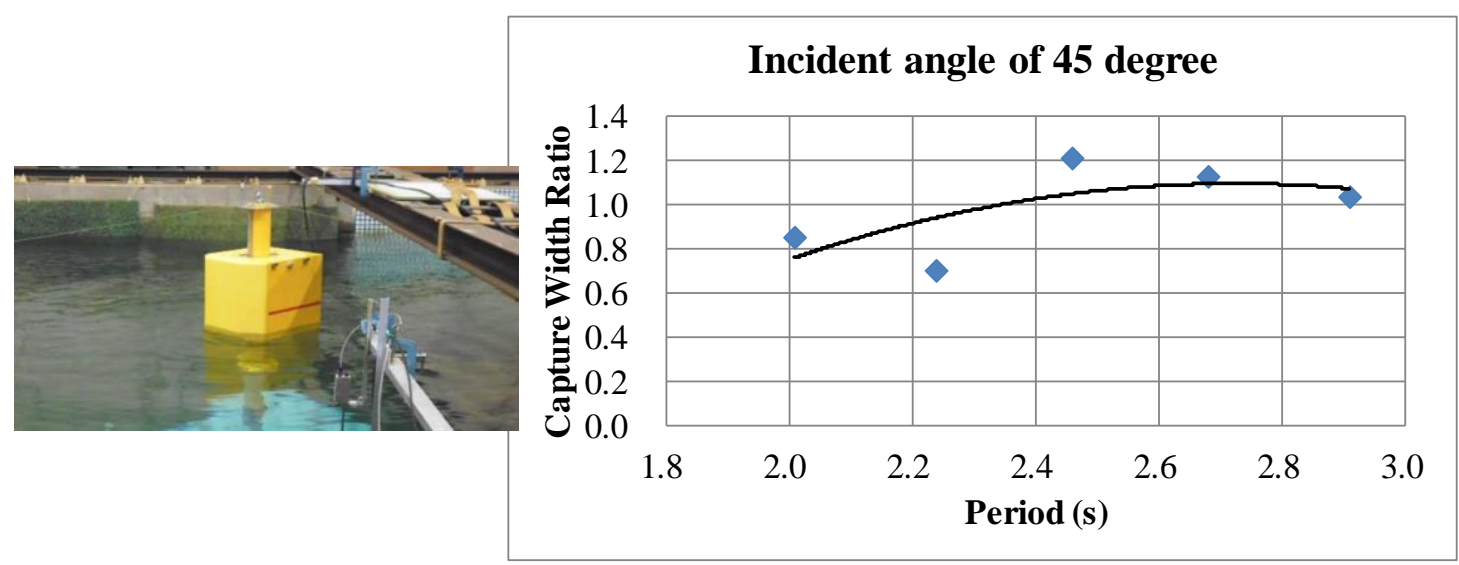

Figure 15. Capture width ratio of the WEC model, for incident wave angle of 45-degree. 


\section{REAL SEA DEMONSTRATION TEST}

\section{Installation}

The WEC was installed at the coastal zone in Oarai port, facing to the Pacific Ocean. (Miyajima et al., 2016) This WEC is at $100 \mathrm{~m}$ from the land and operation is done from a PC in the land. (Figure 16) During stormy weather, the float sinks to the sea bottom to avoid damage. (Figure 17)
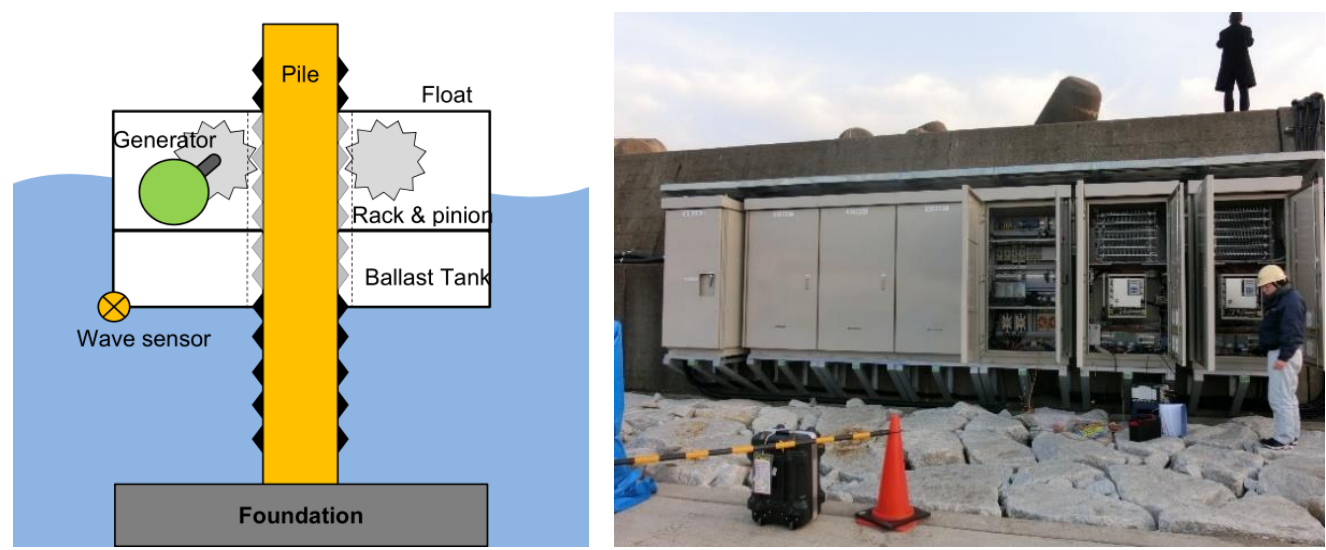

Figure 16. Test WEC structure (left) and control equipment on land (right).
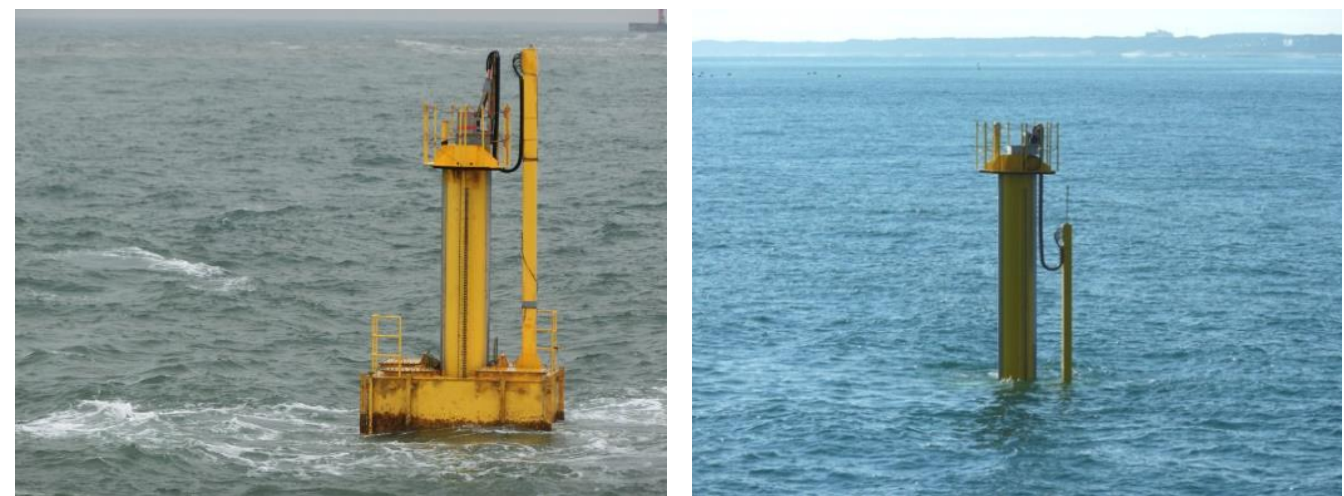

Figure 17. Test WEC at the coastal zone in Oarai port, floating (left) and sinking (right).

\section{Demonstration Test by Optimal Velocity Control}

By using the optimal velocity control as shown in Figure 8, resonance can be easily achieved. Although the resonance is highly efficient, there is a danger that the resonant amplitude becomes excessive in the high wave height. At such times, the control mode is changed to the conventional resistive control using the generator only as a brake. The switching of two control modes is done instantaneous without stopping, as shown in Figure 18.

Figure 18 shows measured data of 30 seconds $(0.1 \mathrm{~s} \times 300$ points $)$. The left vertical axis is $\mathrm{kW}$, and the right vertical axis is kWs. (Float position $(\mathrm{m})$ and wave profile $(\mathrm{m})$ are shared with the left vertical axis $\mathrm{kW}$.) The first $15 \mathrm{~s}$ of Figure 18 is for resonance control and the second $15 \mathrm{~s}$ is for resistive control. In resonance control, we can see the curve of the power generation $\mathrm{kW}$ becomes negative (motoring operation) occasionally, to achieve reactive control. As a result, the position of the float is delayed 90 degree, and the resonance is caused as shown by the arrow in the figure. In contrast, in resistive control, $\mathrm{kWh}$ is small because there is no resonance, though the generation $\mathrm{kW}$ is always positive, and the phase of the float position is same as the incident waves.

Figure 19 shows the wave power generation data for 30s, showing the resonance (Case 1). When three incident waves with the period of about $4 \mathrm{~s}$ come, the float reacts keenly, and it is shown that the maximum generated power is about $6 \mathrm{kw}$ (generator No. 1). Power generation is done in both upward and downward movements of the float and stopped when the velocity of the float becomes zero at the wave crest and trough. That is why we can find six peaks of the power generation from three incident 
waves. The amount of power generation $(\mathrm{kW})$ is obtained by multiplying the torque and the rotating speed of the generator.

Focusing on the 10 seconds at the middle part of Figure 19, the average output Pabs is $4 \mathrm{~kW}$ by dividing 2 sets of $20 \mathrm{kWs}$ by 10s. It is difficult to calculate the incident wave power $\boldsymbol{P} \boldsymbol{w}$, because the data is only $10 \mathrm{~s}$. We approximate the incident waves are regular waves with $\mathrm{T}=4.2 \mathrm{~s}$ and $\mathrm{H}=0.5 \mathrm{~m}$. The incident wave power per unit crest length is $\boldsymbol{P} \boldsymbol{w}=\boldsymbol{H}^{2} \boldsymbol{X} \boldsymbol{T}$, and $\boldsymbol{B}=2.5 \mathrm{~m}$.

$$
C W R=\frac{P_{a b s}}{P w \cdot B}=\frac{4}{2.6}=1.54
$$

Figure 20 shows the torque and RPM of the generator. The two curves look alike, but the signs are reversed. It means that the gear ratio of the generator is designed suitably for this range of frequency.

Figure 21 shows the wave power generation data for 30s, showing another resonance (Case 2). Focusing on the 10 seconds at the middle part of Figure. 20, the average output Pabs is $10 \mathrm{~kW}$ by dividing 2 sets of $50 \mathrm{kWs}$ by $10 \mathrm{~s}$. The incident wave power $\boldsymbol{P} \boldsymbol{w}$ is $3.2 \mathrm{~kW} / \mathrm{m}$ from power spectrum calculation.

$$
C W R=\frac{P_{a b s}}{P w \cdot B}=\frac{10}{3.2 * 2.5}=1.27
$$

Figure 22 shows the torque and RPM of the generator. Though RPM values are $90 \%$ of the rated RPM, the torque are saturated at $160 \%$ (torque limit) of the rated torque. Compared with Case 1, bigger torque is required to cope with the large buoyancy in Case 2. If we use the bigger generators, CWR must be bigger than 1.27 in Case 2, because we can capture bigger Pabs with the bigger generators.

Though the generators are not big enough, we achieved high $\boldsymbol{C W R}$ more than 1.0 for both Case 1 and Case 2 .

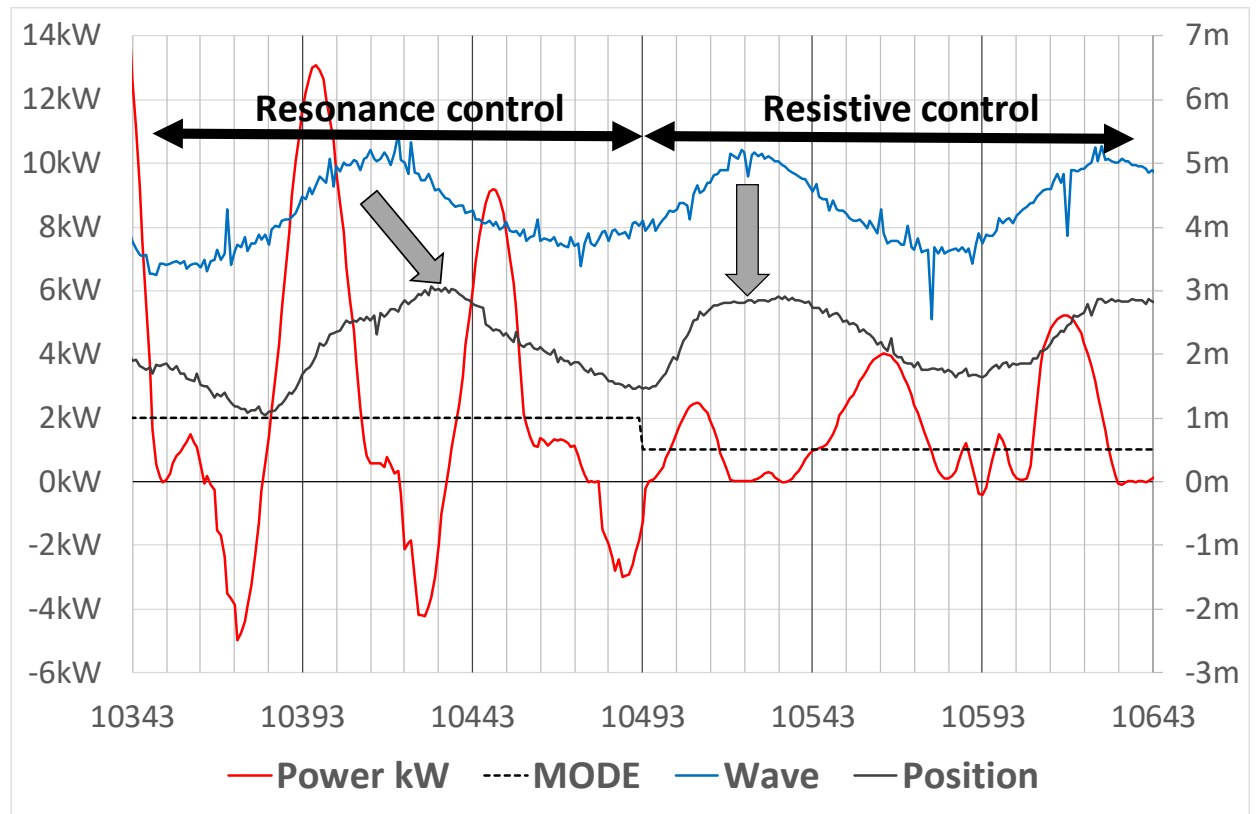

Figure 18. Resonance vs. resistive control. The switching of two control modes is done instantaneous without stopping. The phase shift between the incident waves and the float movement is 90 degree in resonance and 0 degree in resistive control. 


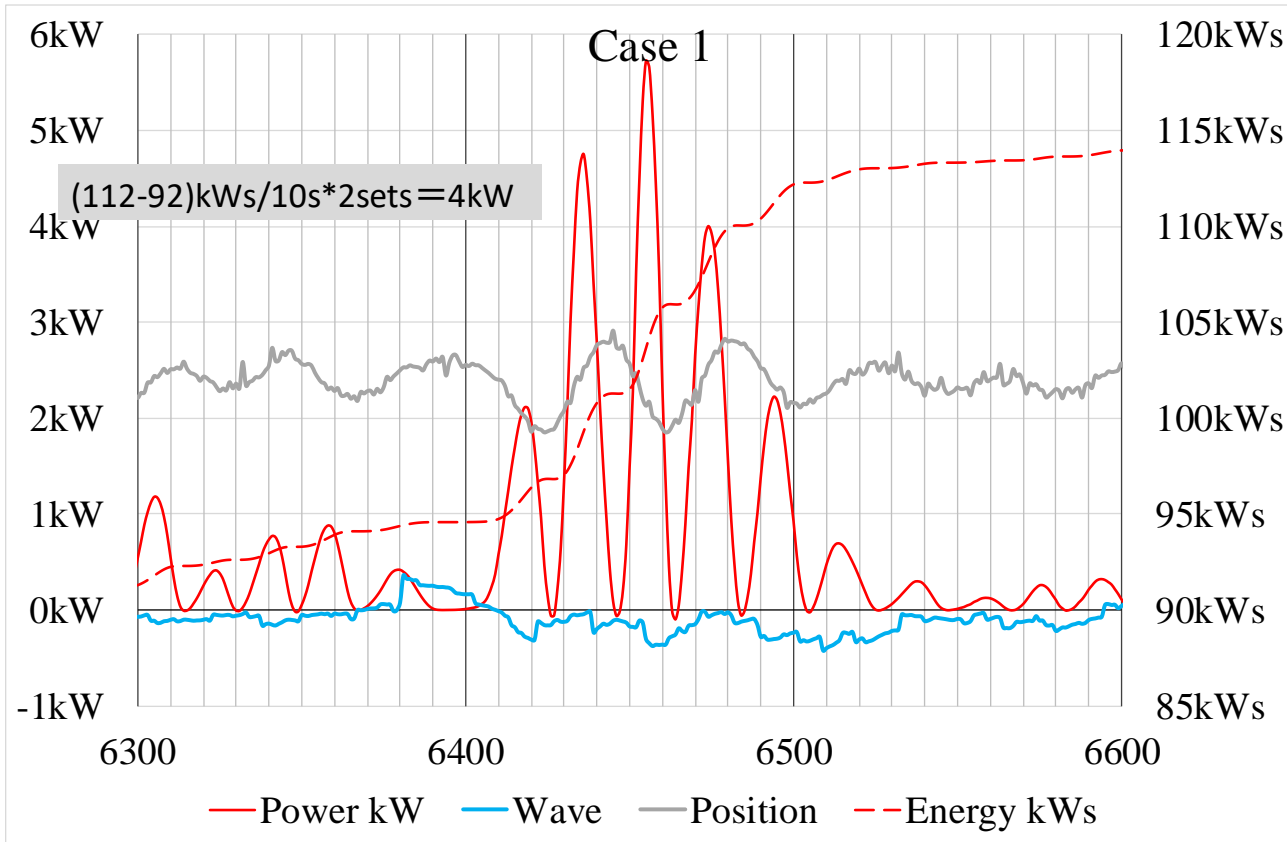

Figure 19. (Case 1) Resonance data, $T \approx 4 s$.

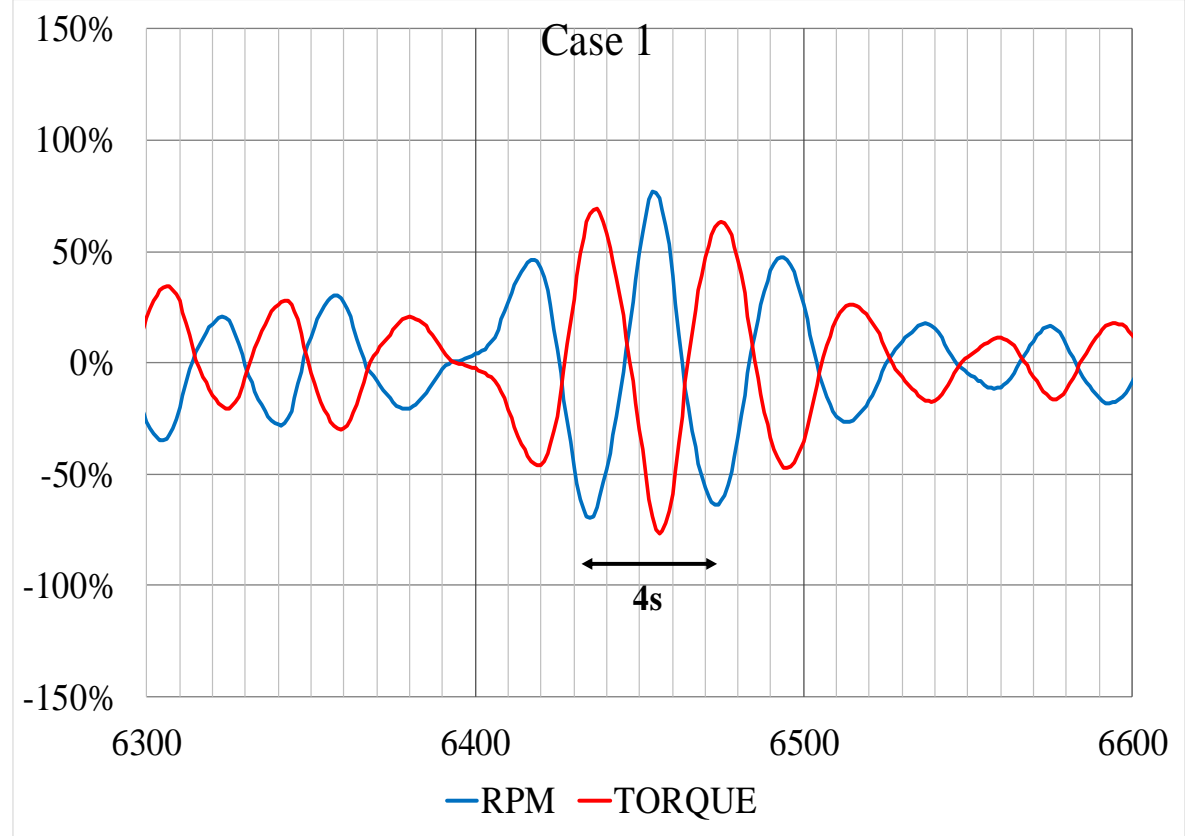

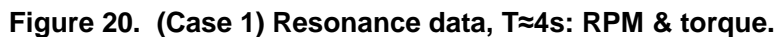




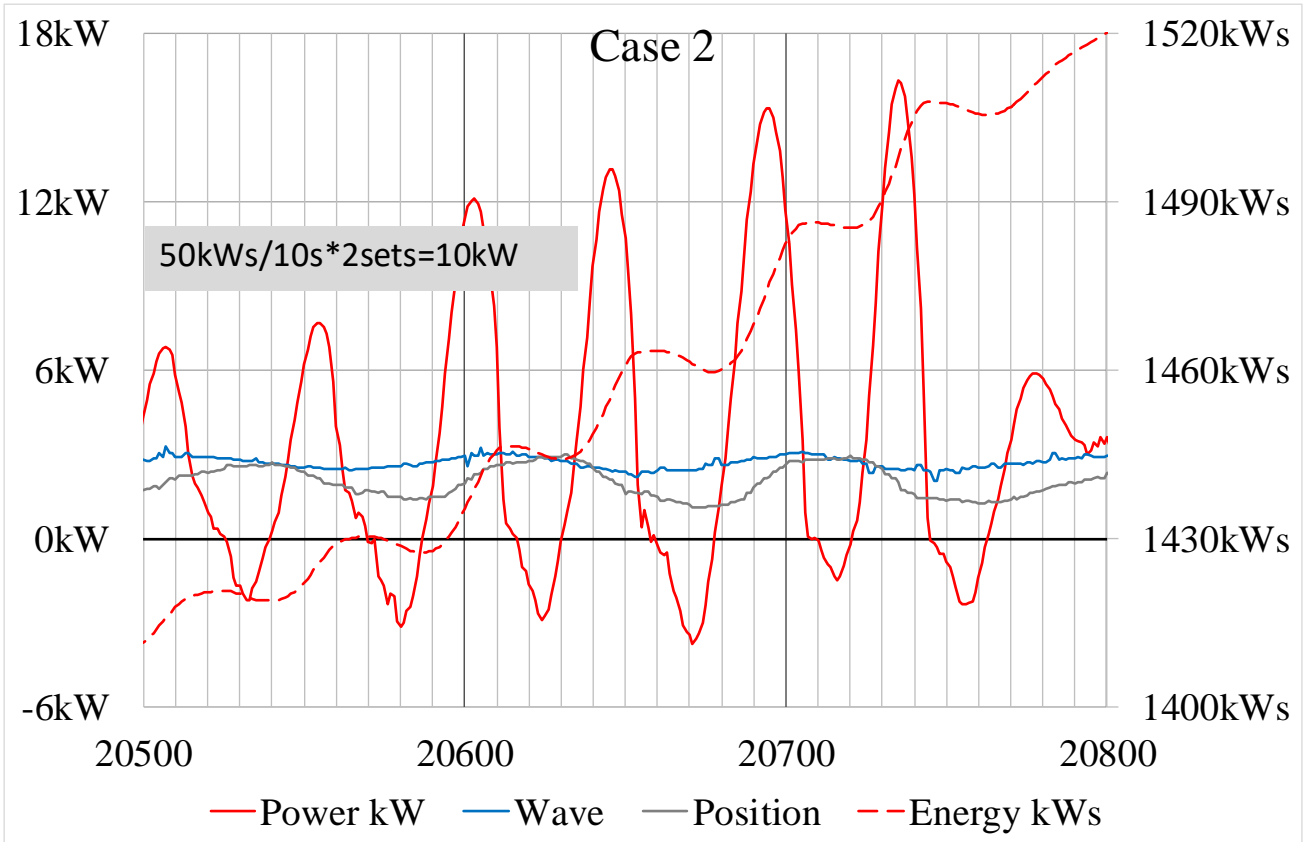

Figure 21. (Case 2) Resonance data, T₹9s.

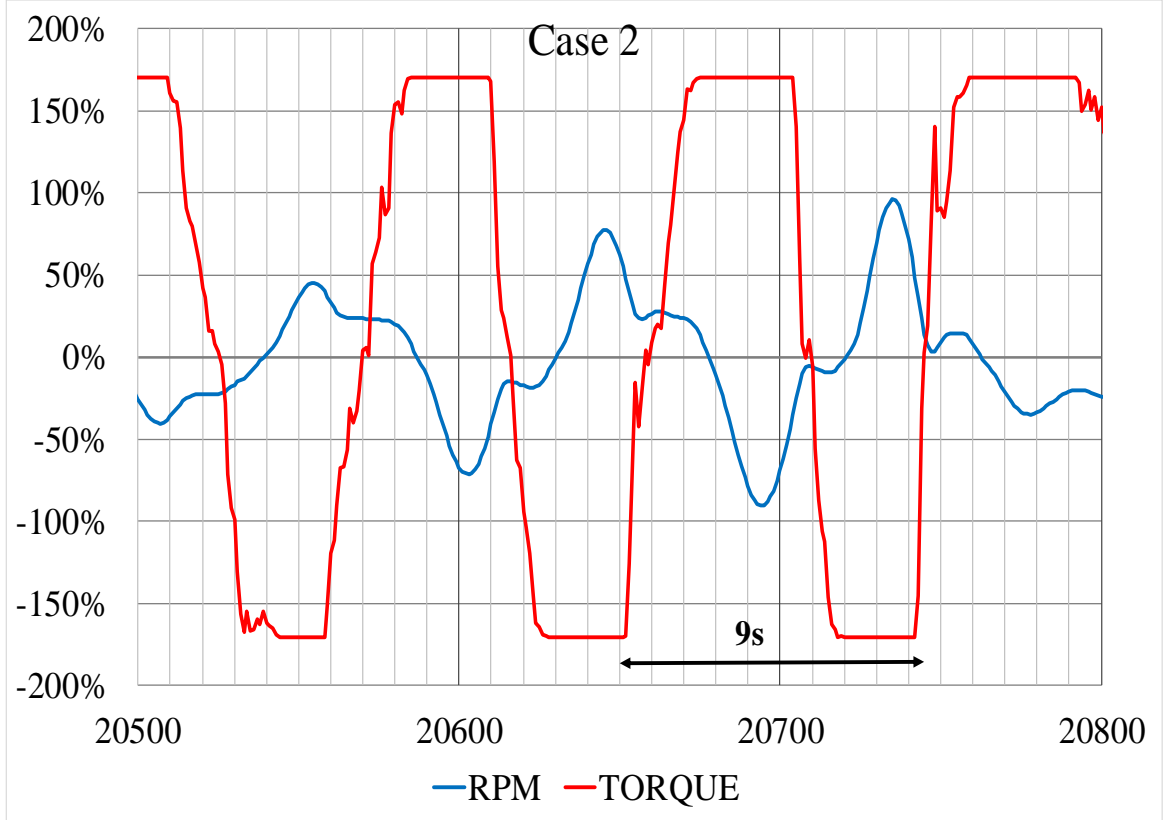

Figure 22. (Case 2) Resonance data, T₹9s: RPM \& torque.

\section{CONCLUSIONS}

The newly developed optimal velocity control, based on the absorbing control, works very well. This method is simple and easy, and it turned out to be very effective. This control is to use velocity control of the float based on the incident wave profile detected by the wave sensor. By this, the resonance condition can be easily achieved because the phase of the float is delayed by $\pi / 2$ for the incident waves by feeding the wave sensor signal to the velocity reference.

We also succeeded to use a box shaped float instead of an axisymmetric float. It is easy to manufacture, and the impact to cost is large. 


\section{ACKNOWLEDGMENTS}

This research was carried out in the project entrusted from Ministry of the Environment, Japan. We have received great cooperation from Ibaraki Prefecture, Oarai Town and Oarai-cho Fisheries Association. We would like to thank all people concerned.

\section{REFERENCES}

Babarit, A. and Hals, J. 2011. On the maximum and actual capture width ratio of wave energy converters, 11th European Wave and Tidal Energy Conference Series (EWTEC 2011)

Budal K. and Falnes J. 1975. A resonant wave point absorber of ocean waves, Nature 256, 478-479

Falnes, J. 2002. Ocean Waves and Oscillating Systems, Linear Interactions Including Wave-Energy Extraction, Cambridge University Press, 196

Falnes, J 2007. A review of wave-energy extraction, Marine Structures 20(4), 185-201

Hals, J., Bjarte-Larsson, T. and Falne, J. 2002, Optimum Reactive Control and Control by Latching of a Wave-Absorbing Semisubmerged Heaving Sphere, The Proceedings of the 21st International Conference on Offshore Mechanics and Artic Engineering

Hirakuchi, H. Kajima, R. and Kawaguchi, T. 1990. Application of a piston-type absorbing wavemaker to irregular wave experiments, Coastal Engineering in Japan, 33(1), 11-24.

Kawaguchi, T. 1986. Absorbing wave making system with wave sensor and velocity control, Tech. Report No. 128, Mitsui Engineering \&: Shipbuilding CO., LTD. (in Japanese), 20-24

Kawaguchi, T., Nakano, K., Miyajima, S. and Arikawa, T. 2018. Wave Energy Converter with Wave Sensor and Velocity Control, Proceedings of the Twenty-eighth (2018) International Ocean and Polar Engineering Conference. 678-684.

Kobayashi, M. and Hineno, M. 1974. Hydrodynamic Forces and Moments, acting on Two-dimensional Asymmetrical Bodies, Tech. Report No. 87, Mitsui Engineering \&: Shipbuilding CO., LTD., 1-14 (in Japanese)

Miyajima, S., Nakano, K., Maemura, T. and Kawaguchi, T. 2016. Development of the coastal wave power generation device, 2016 Techno-Ocean

Salter, SH. 1982. Absorbing wave-makers and wide tanks, Proc. Conf. Directional Wave Spectra Applications, ASCE, 185-202

Salter, SH. 1974. Wave power, Nature, 249, 720

Tanizawa, K., Ueno, M., Taguchi, H., Fujiwara, T., Miyazaki, H., Sawada, H. \& Tsukada, Y. 2011. The Actual Sea Model Basin, Papers of National Maritime Research Institute Vol.10 No.4 (in Japanese) 